Original paper

\title{
Simulation-based training for improving managers' awareness to a crisis: An empirical study to observe the capability of the iCrisis simulation approach to generate crisis at the strategic level
}

\author{
Clément Judek $^{1}$, Frédéric Verhaegen ${ }^{2}$, Abla-Mimi Edjossan-Sossou ${ }^{1}$, Thierry Verdel ${ }^{1}$
}

Received: 30/11/2018 / Accepted: 27/05/2019 / Published online: 22/08/2019

\begin{abstract}
Crisis management concerns have increased in recent years, but it is difficult to gain experience with it except by directly experiencing a crisis situation. Crisis simulations aim to offer this experience. iCrisis is a crisis situation simulation approach that operates on the assumption that it accurately simulates crises. However, no methodology exists that can validate this assumption. The aim of this paper is to determine in the framework of an iCrisis simulation one can observe the crisis characteristics. We first make a literature review to define the concept of crisis; we propose a list of characteristics separated into two categories: the characteristics of a crisis situation and those of the reaction that it raises among the managers coping with it. Second, we present the iCrisis approach, its consideration of the crisis characteristics and how to assess their generation during the simulation. Although the assessment of crisis characteristics is subjective, it is nevertheless relevant to use participants' feelings at the end of a simulation to study these characteristics. Eventually, our observations highlight that the crisis situation characteristics can be observed and perceived by the participants from two studied simulations.
\end{abstract}

Key words: Crisis situation; Crisis simulation; Training; Crisis management.

\section{INTRODUCTION}

For an unprepared organization, handling certain incidents can immerse managers under crisis conditions. Crises are considered to be threats to the survival and the goals of an organization (Fink et al. 1971; Hermann 1963, 1969; Kovoor-Misra 1995; Nystrom and

\footnotetext{
1 Université de Lorraine, CNRS, CREGU, GeoRessources laboratory, Ecole des Mines de Nancy, Campus Artem, CS 14234, Nancy Cedex, F-54042, France.

2 Université de Lorraine, APEMAC (EA4360), 54500 Vandœuvre-lès-Nancy, France.
} 
Starbuck 1984; Pauchant and Mitroff 1992; Shrivastava et al. 1988; Smart and Vertinsky 1984; Ulmer et al. 2013), but they can also serve as opportunities for organizations (Milburn et al. 1983). Therefore, a crisis may have a negative impact but it can also initiate positive developments.

Because crises occur infrequently, crisis managers have few opportunities to gain experience handling such high-consequence situations. Because these situations are unique (Lalonde and Roux-Dufort 2013), managers must develop novel adaptive response procedures under stressful conditions, including uncertainty and time pressure (Wiener and Kahn 1962). Even though each crisis situation is unique, the process of decision making during a crisis situation relies on previous experience (Tena-Chollet et al. 2016) which can be considered as a paradox since a decision must be made based on experiences that are different compared to the on-going situation. It is crucial that managers are alerted to opportunities that arise during a crisis situation; because learning from failures promotes preparedness, these experiences may increase their effectiveness in the future (Carmeli and Schaubroeck 2008; Cesta et al. 2014; Kim and Lee 2011). These experiences can also help to prevent unprepared organizations from allowing a situation to worsen (Starbuck et al. 1978).

Organizations cannot rely on gaining experience from real crisis situation due to its infrequent occurrence nature and its potential severe aftermaths. In this context, simulationbased training has become an increasingly used method by which one could develop crisis management skills (leadership, problem solving, situational awareness, resources allocation, communication, etc.). With ambitious objectives, crisis simulators carry the common idea that they do simulate crisis situations, however no study tends to verify this induced assumption that a crisis simulator simulates crises. In parallel, we can easily imagine that due to the large amount of engaged funding there could be a need of verification (Hartley 1997). For these reasons we would like to know if the crisis simulation approach called iCrisis allows to observe characteristics of the crisis. The iCrisis approach is interesting regarding this objective of this study to observe its capability to simulate crisis because based on the philosophy of this approach, it aims to sensitize the participants of such simulation. Sensitization does not mean assessment, of the implementation of a procedure, but it means opening minds to people's reactions during an unknown and unpredictable situation from which crisis units have to steer out.

This paper proposes to make an empirical study of the capacity of iCrisis simulation approach to generate crisis characteristics. This study was carried out as part of the CascEff project (Seventh Framework Programme EU project CascEff-Modelling of dependencies and cascading effects for emergency management in crisis situations), which aims to develop a cascading effect modelling tool. The remaining part of this paper is structured as follows: we first tend to provide a definition of the concept of crisis through describing crisis characteristics, then present how to generate them through the simulation process and assess that they are present. Afterward the results are briefly presented and eventually, the paper concludes with a summary of findings and the corresponding implications as well as the limitations of the study. 


\section{HOW TO DEFINE THE CRISIS?}

A clear definition of a crisis is necessary to differentiate it from other critical situations, such as accidents and emergencies. This differentiation is essential for designing the conditions and the scenario in a simulation.

The literature gives many definitions for the concept of crisis, which can cause confusion. For example, various authors have incorporated opposing components, including threats (Hermann 1969; Kovoor-Misra 1995; Nystrom and Starbuck 1984) and opportunities (Fink and American Management Association 1986; Milburn et al. 1983), as well as surprising (Hermann 1969; Pearson and Mitroff 1993) and predictable (Milburn et al. 1983). Flin (1996) and Sniezek et al. (2001) defined a crisis as a special situation with its own characteristics defined by uncertainties, a quick onset, temporal constraints, significant short-term losses (human and economic), a lack of controllability and a high level of stress. Despite these sometimes diverging definitions, Pauchant and Douville (1993) propose a definition that should be acceptable to most authors; for them, crises "are disruptive situations affecting an organization or a given system as a whole and challenging previously held basic assumptions; they often require urgent and novel decisions and actions, leading potentially to a later restructuring of both the affected system and the basic assumptions made by the system's members".

At first glance, the diversity of definitions found in the literature for the concept of crisis seems confusing. This can be explained by two elements: the need to define this key concept when working on it and the fact that it is used in large variety of domains (from disaster management to politics and healthcare etc.). When reading the broad array of definitions in the literature, although they seem to provide different meanings and bring confusion, the features proposed by authors to characterize the crisis in their definition looks very relevant. To manage this issue of understanding as well as the issue of consistency regarding previous work, despite proposing a new definition of the concept of crisis, we based our reflection on the characteristics given by the literature. Once gathered, it looked clear that they converge on two aspects when describing the concept of crisis. Therefore, we came up with two categories of characteristics which define a crisis:

- The characteristics of a crisis situation;

- The characteristics of the managers' perception and reaction to a crisis situation

\section{Crisis situation characteristics}

The literature characterizes the crisis a lot, this process seems interesting to help the reader understand this complex concept. Regarding the crisis situation, authors characterise it using a large panel of vocabulary. However, it is common that different words actually mean the same characteristic and for this reason, we propose ten characteristics (Table 1) and we explain each of them regarding the literature. 


\section{Chaos}

The term chaos is often used to describe a crisis (Lagadec 1993; Zhang et al. 2012), but other descriptions suggest similar or associated characteristics, such as a "new and unknown situation" (Wiener and Kahn 1962) and "unique and exceptional" (Lalonde and Roux-Dufort 2013). As a confusing situation of disorder leading to disorderly behaviour (Zhang et al. 2012), chaos can describe many new situations; it is therefore unique when it happens, in contrast to a known situation in which previous experience tends to prevent chaos.

Table 1. Characteristics of a crisis situation

\begin{tabular}{|c|c|}
\hline Characteristics & References \\
\hline Chaos & $\begin{array}{l}\text { Wiener and Kahn 1962; Lagadec, 1993; Zhang, Jia, and } \\
\text { Gu 2012; Lalonde and Roux-Dufort } 2013\end{array}$ \\
\hline Unexpectedness & $\begin{array}{l}\text { Rosenthal, Boin, and Comfort 2001; Bundy and Pfarrer } \\
\text { 2015; Herman 1972, Farazamand, } 2001\end{array}$ \\
\hline Important consequences & $\begin{array}{l}\text { Pearson and Clair 1998; Farazmand 2001; Sniezek, } \\
\text { Wilkins, and Wadlington 2001; Carmeli and } \\
\text { Schaubroeck 2008; Bundy and Pfarrer } 2015\end{array}$ \\
\hline Uncertainty & $\begin{array}{l}\text { Wiener and Kahn 1962; Lagadec 1991; Gredler 1992; } \\
\text { Farazmand 2001; Rosenthal, Boin, and Comfort 2001; } \\
\text { Sniezek, Wilkins, and Wadlington 2001; Boin 2004; } \\
\text { Bundy and Pfarrer } 2015\end{array}$ \\
\hline Evolving nature of the problem & Lagadec 1991; Farazmand 2001; Zhang, Jia and Gu 2012 \\
\hline Irregular rhythm & Lagadec 1991 \\
\hline Numerous stakeholders & Lagadec 1991; Pearson and Mitroff 1993 \\
\hline Information management issues & $\begin{array}{l}\text { Wiener and Kahn 1962; Milburn 1972; Jannis and Mann } \\
\text { 1977; Billings, Milburn, and Schaalman 1980; Gredler } \\
\text { 1992; Pearson and Clair 1998; Boin 2004; Carmeli and } \\
\text { Schaubroeck } 2008\end{array}$ \\
\hline Media involvement & Lagadec 1991; Reid 2000; Bundy and Pfarrer 2015 \\
\hline
\end{tabular}

\section{Unexpectedness}

The literature often defines a crisis as a consequence of an event or situation that is unexpected (Bundy and Pfarrer, 2015; Hermann, 1972; Rosenthal et al., 2001) or difficult to predict (Farazmand 2001). 


\section{Uncertainty}

Crises are often associated with uncertainty (Bundy and Pfarrer 2015; Gredler 1992). In his description of crises as a situation that involves "more than uncertainties: the unknown," Lagadec (1991) noted that uncertainty can arise from the unknowable nature of an event's cause, extent or duration (Sniezek et al. 2001), as well as its evolution, since "no one seems to be able to predict the chain of events or the possible outcomes" (Farazmand 2001). In addition, during a crisis, communication can help lowering the uncertainties regarding the nature of the event; however, one person's idea of clear information may not match someone else's; this can impart additional uncertainty. All of these uncertainties make assessing the situation difficult (Wiener and Kahn 1962).

\section{Important consequences}

Crisis situations have impacts that are large (Carmeli and Schaubroeck 2008; Pearson and Clair 1998) and widespread (Bundy and Pfarrer 2015), leading to severe losses (Farazmand 2001; Sniezek et al. 2001).

\section{Evolving nature of the problem}

A crisis does not remain stable; otherwise, it would end. What makes a crisis situation to persist is the fact that it evolves (Lagadec 1991) both dramatically and rapidly (Farazmand 2001).

\section{Irregular rhythm}

The temporal rhythm of a crisis situation is not fixed. Periods of inaction alternate randomly with periods of rapid change (Lagadec 1991).

\section{Numerous stakeholders}

The increasing number of stakeholders involved in crisis management means that a large variety of actors participate, and these people can ease or complicate the process of coping with a crisis (Lagadec 1991; Pearson and Mitroff 1993).

\section{Information management issue}

Crises often have multiple explanations, ambiguity regarding responsibility and potential damages, and several feasible solutions (Billings et al. 1980; Pearson and Clair 1998). This information is shared between numerous stakeholders. The large number of actors sending information can result in information overload (Milburn 1972) for crisis managers. In addition to the high volume of information being transmitted, messages can be inadequate (Gredler 1992) if the information was not transmitted to the right person or is incomprehensible because of its technical vocabulary. Paradoxically, despite the large amount of information present, the most critical one may not be available (Wiener and Kahn 1962) because information is often incomplete or conflicting (Carmeli and Schaubroeck 2008). Consistent information management is the process through which relevant information is provided to the correct decision makers (Anand et al., 1998) during a crisis. 


\section{Media involvement}

A crisis usually involves the media. They scrutinize the situation (Reid 2000) and may enhance the large-scale impact of information or rumours (Lagadec 1991), making the crisis situation a collectively perceived event (Bundy and Pfarrer 2015). The media can be both aggressive and tenacious if they believe that there is a story to tell (Reid 2000).

\section{Characteristics of the managers' perception and reaction to a crisis situation}

In this part, we tend to present the characteristics of the managers' reaction to a crisis that they are coping with. This second category of characteristics has received less attention in the literature based on the number of relevant studies (Table 2). While defining the crisis, authors focus on the situation. However, due to the fact that this situation needs to be managed anyhow, some authors characterized the situation with the pitfalls that it carries.

Table 2. Characteristics of the participants' reaction in the context of a crisis situation

\begin{tabular}{ll}
\hline Characteristics & References \\
\hline Astonishment & $\begin{array}{l}\text { Hermann, 1963; Hermann 1969; Hermann 1972; Pearson and } \\
\text { Mitroff 1993; Zhang, Jia, and Gu } 2012\end{array}$ \\
& Wiener and Kahn 1962; Hermann 1972; Billings, Milburn, and \\
Due to time pressure & Schaalman 1980; Quarantelli 1988; Rosenthal, Charles, and Hart \\
& 1989; Lagadec 1991; Gredler 1992; Pauchant and Douville 1993; \\
& Farazmand 2001; Rosenthal, Boin, and Comfort 2001; Sniezek, \\
& Wilkins, and Wadlington 2001; Boin 2004; Zhang, Jia, and Gu \\
& 2012
\end{tabular}

Relative nature of the Miller 1963; Lagadec 1991; Kovoor-Misra et al., 2001

crisis

Anxiety

Wiener and Kahn 1962, Miller and Iscoe 1963; Flin 1996;

Sniezek, Wilkins, and Wadlington 2001; Perry 2007; Perghel and

Psychogios 2013

Changes in relationship Wiener and Kahn 1962; Miller and Iscoe 1963; Milburn 1972;

Gredler 1992; Ramboatiana and Roux-Dufort 2006

\section{Astonishment}

This characteristic results from the aspect of unexpectedness previously described. It is logical that the human reaction to an expected event is astonishment and surprise. Zhang et al. (2012) proposed this causal link in the definition of a crisis by saying that it results in people being astonished or in other terms surprised (Hermann 1963, 1969; Pearson and Mitroff 1993). 


\section{Due to time pressure}

Descriptions of time pressure are common in the literature, reflecting the perception of decision makers in crisis situations. The severity of a crisis situation requires an immediate reaction (Hermann 1972) and urgent decisions (Pauchant and Douville 1993). In addition to decisions, feedback is urgently needed (Billings et al. 1980), although there is little time to respond (Quarantelli 1988). These factors result in time pressure (Gredler 1992; Rosenthal et al. 1989) on the people coping with the situation. The word urgency (Boin 2004; Farazmand 2001; Lagadec 1991; Rosenthal et al. 2001; Sniezek et al. 2001; Wiener and Kahn 1962; Zhang et al. 2012) illustrates the need to quickly solve the problems inducing time pressure for crisis managers.

\section{Relative nature of the crisis perception}

Crisis represents the breakdown of individual frames of reference (Lagadec 1991). Each individual has his own frame of reference, formed by his experience, knowledge and emotional state. Therefore, people experience crises differently (Kovoor-Misra et al. 2001) and crisis states are relative: a crisis for one person may not be a crisis for another (K. Miller and Iscoe 1963).

\section{Anxiety}

Crises cause anxiety (Miller and Iscoe 1963; Wiener and Kahn 1962) that can equate to a high level of stress (Flin 1996; Sniezek et al. 2001). Perghel and Psychogios (2013) suggest that a crisis is a time of acute stress that should not be confused with chronic stress.

The concepts of stress and anxiety are often used in an equivalent manner. Although the two concepts are related, they differ biologically; they are difficult to differentiate and thus to measure.

Stress is a behavioural, emotional, cognitive and physiological response to a stressor (Lazarus and Folkman 1984). First described by Seyle (1956), it involves a physiological reaction that allows the body to face external aggression. This reaction is characterized by three phases: the alarm phase, during which the body mobilizes its defences; the resistance phase, during which adaptation to the stressor occurs; and finally the exhaustion phase, which occurs if the stressor is too strong or goes on for too long, meaning that the body cannot cope with it. Both the alarm and resistance phases are considered to be beneficial and positive because they allow a person to adapt and control the effects of the stressor. However, the exhaustion phase is considered to be negative because it involves a failure to adapt to assault.

In contrast, anxiety describes an unpleasant emotional state that is usually temporary (Spielberger 1983). This state exists at a given time and at one level of intensity; it is characterized by tension, apprehension and nervousness. Therefore, the definition of anxiety focuses on the state of the participant, while the definition of stress focuses on the relationship of the participant with their environment. 


\section{Changes in relationship}

Crisis situations create tension between the people that experience it (Gredler 1992; K. Miller and Iscoe 1963; Wiener and Kahn 1962), as well as internal conflicts (Milburn 1972) that can lead to changes in relationship (Wiener and Kahn 1962). Crisis situations often trigger excessive emotional and affective demonstrations (Ramboatiana and Roux-Dufort 2006) such as arguing or scapegoating someone.

\section{DO CRISIS SIMULATIONS SIMULATE CRISIS?}

Crisis simulation is intended to allow managers to cope with a virtual but realistic crisis situation that raises opportunities for the organization experiencing it. To create simulations capable of creating such opportunities, it is important to verify that the simulations reproduce the specific conditions of a crisis, as well as to ensure that managers experience the most realistic crisis environment possible (Borodzicz and Van Haperen 2002). Crisis simulators propose to increase awareness by placing people under crisis conditions. They aim to reproduce the atmosphere of a crisis as precisely as possible, knowing that it is subjective to anyone and recalling that one of the characteristics of the crisis is the relative nature of the crisis perception. Simulations mimic a real-world process or system over time; thus, crisis simulation approaches propose to imitate real-world crisis situations. However, we have mentioned earlier that it is difficult to define crisis situations because of their unique and relative nature. This problem of definition complicates the need to ensure that crisis simulation approaches actually simulate crises. According to Gredler (1992), crisis simulations should produce the same reactions and feelings in participants as real-life crisis events. Borodzicz (2004) stated that simulations should reproduce as accurately as possible the fundamental elements of a crisis (considered as the pre-cited characteristics here in this study) to allow the participants to experience crisis conditions. Therefore, we assume that if a simulation can arouses the participants' reaction characteristics to a crisis, then the characteristics of a crisis situation have been simulated well. Previous research has noted that no validation methodology exists for simulations (Feinstein and Cannon, 2002; Hays and Singer 1989).

Some studies have assessed the on-technical skills required to manage a crisis, including decision-making (Dautun et al. 2007; Hadley et al. 2011; Sommer and Pearson 2007) and leadership (Amabile et al. 2004; Boin et al. 2013; Hadley et al. 2011; Tena-Chollet 2012; Yusko and Goldstein 1997). These studies were based on observations made during crisis simulations. However, even for simulations that involved crisis-like characteristics, such as information overload, ambiguity and urgency, no existing crisis simulation approaches have shown that their participants experienced the characteristics of a crisis situation. One exception is proposed by Sneizek et al. (2002), who suggested that the computer-based simulator "DC-Train" was psychologically realistic after testing the human performance of its trainees. This study shows that it is possible to create a methodology to test whether a crisis simulation approach recreates the psychological effects specific to a crisis situation. 
Amongst the existing simulators, iCrisis is an organizational and technical system developed from crisis simulation experiments that have been conducted with students and professionals (Verdel et al. 2010). This crisis simulation approach is often used with the objective of raising participants' awareness regarding the "steering process" of a crisis situation. With respect to the participants thinking that they experience a crisis situation as well as for scientific purposes, it is relevant to make sure that iCrisis simulates what it states.

\section{MATERIAL AND METHOD}

To observe that iCrisis simulation can recreate a crisis situation, we examined whether it can reproduce the characteristics of a crisis situation and whether the participants perceive the characteristics of reaction to a crisis. We analysed data from two iCrisis simulations carried out in 2015. The choice of taking two simulations relied on the fact that it was important to have at least two different groups of participants in order to have a first opinion that the approach of simulation override the environment effect. The other reason why only two simulations have been selected is the fact that preparing and carrying out one is a heavy process that needs time, especially, to get the acceptance of the group who will participate. The simulations involved 119 participants from France. A first group was formed by 45 professionals, who are members of the local crisis units from 4 municipalities of the Meurthe-et-Moselle department. As members of local crisis units composed of mayors, executive directors, assistants and directors of dedicated activities (e.g. roads, schools etc.), their sensitization about crisis situations depended on their own experiences and their opening mind. A second group was formed of 74 students from the Institut Régional d'Administration de Metz, a French institute that trains and teaches future territorial managers who are about to work in Prefectures. The peculiarity of these students is that they are sensitized about crisis situations whereas they don't have much experience yet. Members of both groups are used to work together. The simulations that both groups attended were between two and three hours long and were carried out with iCrisis approach. In response to a simulation of coping with a winter storm, the professionals played their own roles within their municipalities; the students played prepared roles representing the broader strategic level of France's Prefecture. No comparison objective between professionals and students was set since it was not the purpose of this study even though the results for both are displayed. In this part, the iCrisis simulation approach is presented in details regarding how it implements the characteristics of the crisis situation and then we expose how to control the reaction of participants.

\section{iCrisis simulation approach}

The iCrisis simulation approach that has been developed at University of Lorraine (www.icrisis.com) belongs to the category of virtual simulations in real size, involving only crisis units (also known as command posts) at a strategic level organized as a "table top exercise" (Figure 1). Unlike some approaches encountered in this category, it does not rely on any 
computerized modeling. The plausibility of the scenario relies on the knowledge of experts who help to design the scenario prior the simulation and who help to adapt the storyline in live to fit with the participants' reactions. The simulations run using iCrisis execute an open scenario; that is, only the context of the scenario remains fixed. The story itself is left flexible to fit with the behaviour of the participants, which is not foreseeable.

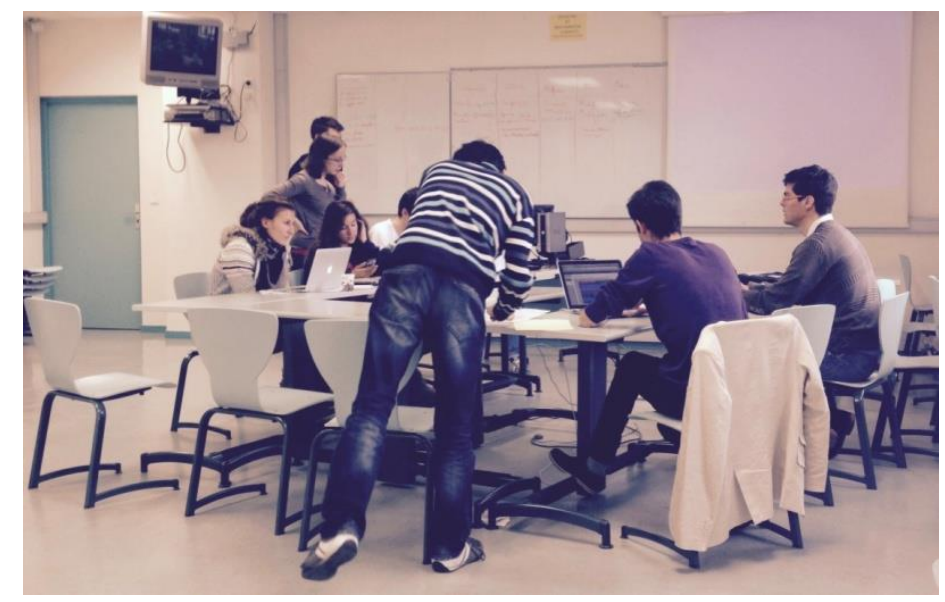

Figure 1. Inside a strategic crisis unit during an iCrisis simulation

The tool iCrisis is a multi-player web-based application which could be simultaneously used on several networked laptop-computers. Based on html5, the iCrisis application can be used anywhere without any installation. Thus, it can be used by groups of decision makers who are physically far from each other. The configuration of the simulation is set by the simulation administrator for any number of crisis units involved in each simulation. The communication is strictly made through the iCrisis application by sending written messages presented on the main page of the tool (Figure 2).

An iCrisis simulation involves one to several physically separated crisis units (Figure 3), an animation team and a media office. The crisis units generally consist of a Prefecture command post (at the county level), a Municipality command post and a Company command post, all of which are connected by the application. However, any configuration at a strategic level is possible. Groups can exchange messages (see full line arrows in Figure 3); the animation team can exchange messages with all groups and also receives copies of all messages exchanged (see dashed arrows in Figure 3) through the iCrisis application. Journalists act as free agents and can visit the different crisis units to gather information. Their role is important since their interactions with the players and their interpretation of the information they gather can create disturbances. These interconnections and the presence of observers (see solid grey arrows in Figure 3) allow the animation team to adapt the storyline based on the participants' reactions. In addition, to maintain a clear view of events, exchanging information by written messages during the iCrisis simulations is necessary because it allows the creation of a database that can be used to analyse the process during debriefing.

Each simulation is followed by a debriefing that lasts for approximately two hours. The debriefing is the opportunity for the participants, the facilitators (from the animation team) and 
the journalists to share their experiences of the simulation. During the debriefing, participants from each crisis unit relate their experiences. The journalists present a press article and/or a TV news report based on the information they gathered during the simulation and facilitators talk about the difficulties involved in dealing with the crisis situation and increase participants' awareness. Eventually statistics of the simulation are presented. They are generated by the application thanks to the data base of the whole exchanges inter-groups that is created during each simulation.

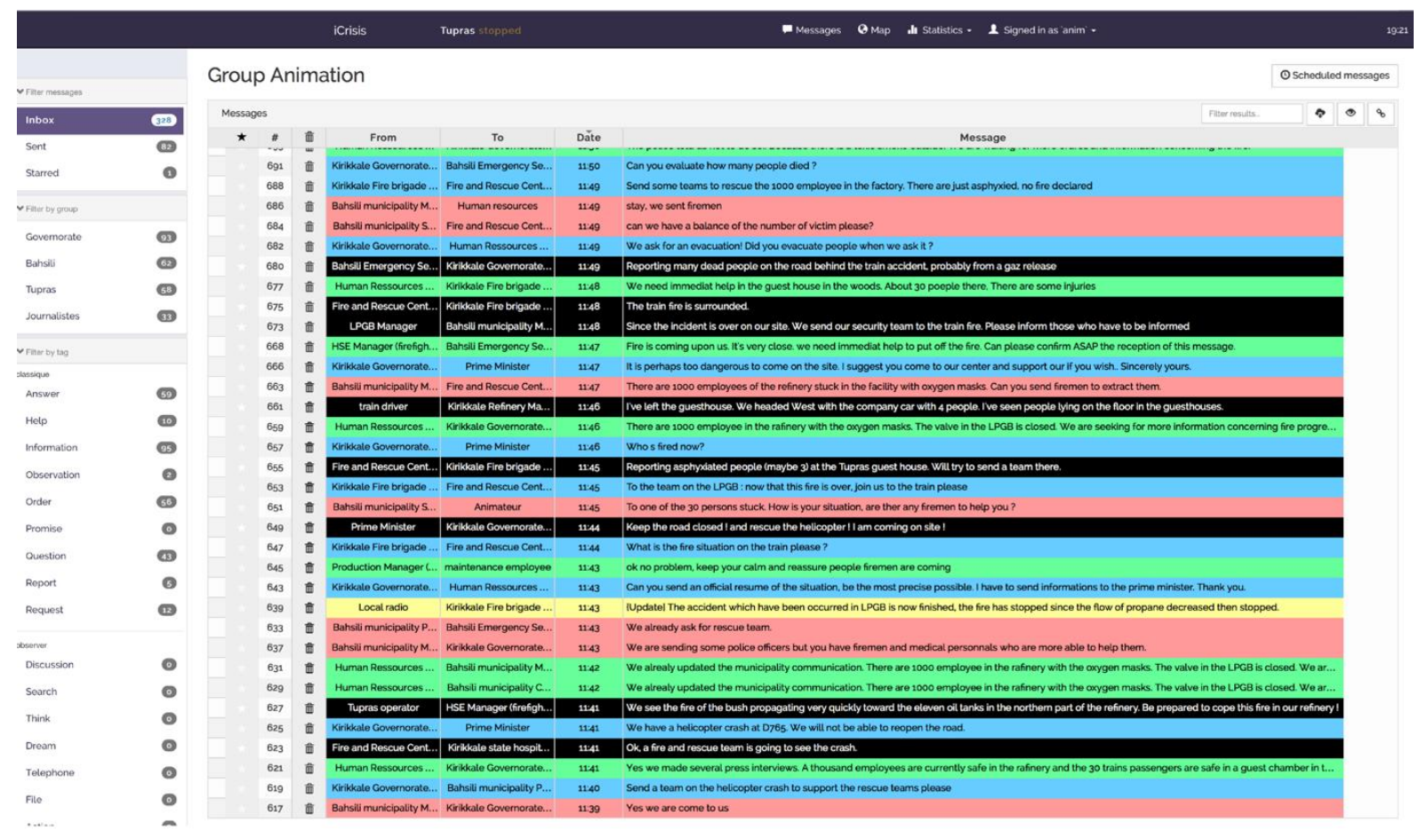

Figure 2. iCrisis exchanged messages interface

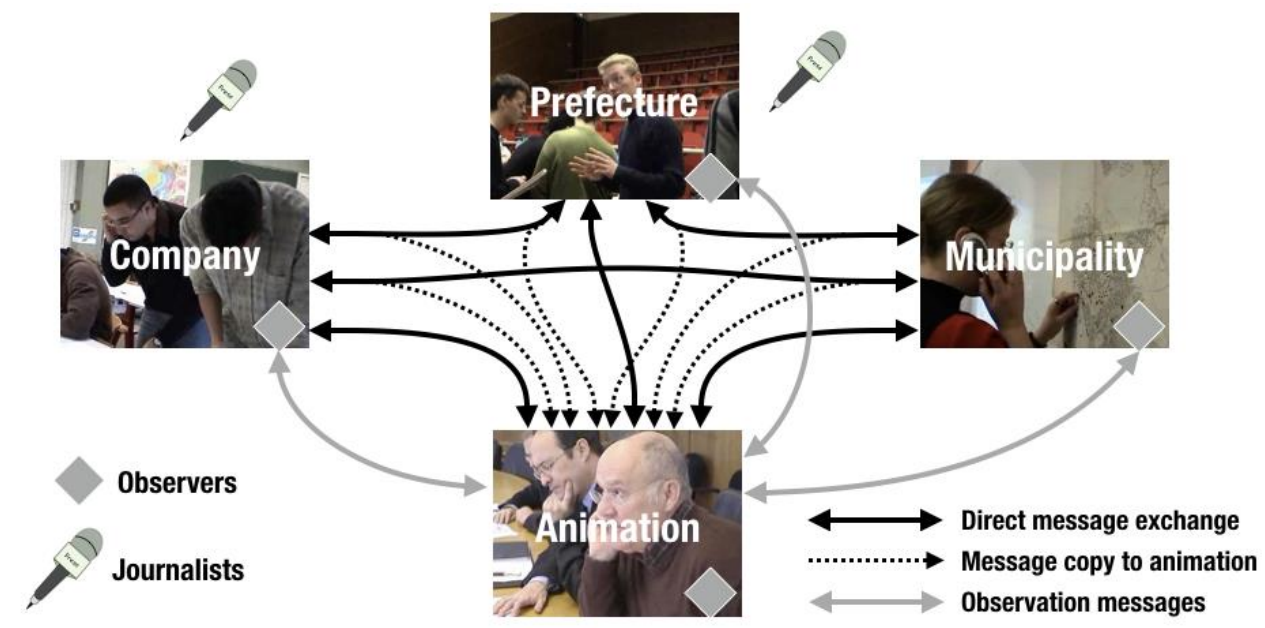

Figure 3. General overview of the iCrisis simulation approach (arrows represent the flow of information via text messaging). 


\section{Generation of a crisis situation}

The iCrisis approach begins with a given scenario but then allows for adaptation of the story depending on how the participants chose to cope with the situation. Thus, the facilitators can easily implement the characteristics of their chosen scenario. The context of the scenario and the role-playing methodology both allow the crisis situation to be established.

Through the imagined events of the scenario, the story includes the evolving nature of the problem; for example, starting with a snowfall warning that evolves until the occurrence of the snowfall. It initially includes slight problems such as people falling, but eventually much larger problems occur, such as severe weather conditions. These problems have important consequences that can be both structural (blocked roads and power outages) and organizational (regular plans and procedures becoming ineffective). This main storyline is supplemented with routine incidents, forcing the participants to cope with the larger events as well as dealing with everyday problems leading to unexpected events. The number and diversity of events requires the involvement of many stakeholders, who are progressively included. The combination of everyday incidents that cause delays due to the lack of available resources, in addition to rare or unusual events that require innovation to design an adequate response, contributes to a situation characterized by complete disorder and confusion (definition of the chaos) among the participants.

The iCrisis platform implements some crisis situation characteristics by the addition of information depending on the scenario and on participant reactions. The content of the message influences the nature of the information, conveying uncertainty. To increase the uncertainty in the minds of the participants, the nature, extent, duration and consequences of the events must remain unclear. A message sent by the animation team (always playing a specific role for that message) could be perceived as urgent because it describes a situation as requiring an urgent response; this could be exacerbated by repetition or by giving shocking details. In addition to message content, the tempo of messaging is important because makes the participants feel that the rhythm of events is irregular and unpredictable, alternating between slow periods and rapid sequences of events. The creation of an irregular rhythm relies on the storyline as well as on the cadence of messaging. Careful control of the information given to participants in a noisy room can help induce information management issues for the participants. A loud environment in a crisis unit can have as consequence to influence the capability of people to stay focused and therefore leads to difficulties to manage to high flow of information. Without being erroneous, some messages are intentionally ambiguous and/or have information that is not appropriate to the person who is receiving the message.

To implement media involvement in the iCrisis simulation, between 2 and 6 participants are identified as journalists. A facilitator briefs them on behaviour characteristic of journalists, including tenacity, aggressiveness and scrutinizing the situation. In the iCrisis simulations, journalists are free to move between groups and ask questions to anyone. The participants in the crisis units can then react as they wish. These interactions make the information in the simulation to evolve. The objective of the journalists is to create an article or a TV report to be shown during the debriefing period. 


\section{Measurement of the participants' reaction to the simulated crisis situation}

To estimate the reaction of the participants dealing with the simulated crisis situation, we made a survey regarding the cited characteristics which was a document that was distributed to the participants who filled it immediately after the simulation. This survey has been divided into two parts: validated questionnaires to analyse the anxiety and the time pressure as a first part and questions to analyse the astonishment, the changes in relationship and the relative nature of the crisis as a second part because no validated tool focusing on these last characteristics exist and could have been exploited. The choice of surveying through simple questionnaires has been made taking into the environment of the simulation, because we feared that psychological tools to assess such parameters being long to fill up would have had as a consequence to take the participants out from the context of crisis.

Anxiety was measured using the State-Trait Anxiety Inventory Form Y (STAI-Y), which was developed by Spielberger in 1983. For this study, we used the French version validated by Bruchon-Schweitzer and Paulhan (1993). Participants rate each of the twenty items with a score of 1 ("not at all"), 2 ("somewhat"), 3 ("moderately so") or 4 ("very much so"), yielding a total score ranging from 20 to 80 . This scale has mainly been used to investigate emotional reactions during crisis steering situations. The instructions given to the participants were as follows: "A number of phrases that are used to describe yourself are given below. Read each sentence and check the box that best matches what you feel now. There are no right or wrong answers. Do not spend too much time on either of these proposals, and indicate the answer that best describes your current feelings." To interpret this scale, a threshold of 39-40 has been suggested (Addolorato et al. 1999; Knight et al. 1983) to clinically identify the symptoms of a state of anxiety.

To evaluate time pressure during the simulation, we used item 4 of the NASA Task Load Index (NASA-TLX) test (Hart and Staveland 1988). This tool is a short questionnaire that subjectively measures the individual workload through 6 items: Frustration; Performance; Physical demand; Temporal demand; Effort; Mental demand. To assess one should put a line on a one-dimensional line segment that goes from 0 to 100. On the left side, 0 denotes very low time pressure and on the right side, 100 denotes very strong time pressure. The instructions given to the participants were as follows: "On the axis located below the question, which goes from 0 to 100, where 0 is "very low time pressure" and 100 is "very strong time pressure", what pressure did you feel during the execution of tasks? Put a line or a cross on the line to the place that best fits how you felt."

Two questions probed the participants' feelings about based on a Likert scale (with 7 levels from "never" to "all the time"): their perceived astonishment; and perceived changes in relationship. Using a 7-grade scale allows to assess how much these characteristics were felt by the participants. However, for the concern of our study, the purpose was to highlight whether these features were felt. The matter of the intensity of the feeling will be certainly used as a perspective. Therefore, this grading was only used as making a distinction between the first grade "never" and the rest. 
Regarding the relative nature of the crisis, we asked the participants to evaluate (with yes or no) whether they would characterize the simulated situation that they experienced as a crisis situation.

\section{RESULTS AND DISCUSSION}

In this part, we present how did crisis situation characteristics were adequately simulated by giving observations and we propose to present and discuss the reaction of participants illustrated by questionnaires' answers. Two groups are displayed: professionals and students to let the reader have an overview that among the type of participants and the fact that a crisis is relative to anyone, the perception of the crisis characteristics are following a similar logic.

\section{Situation characteristics}

During the simulations carried out with iCrisis, a database is automatically created because information is transferred via electronic messages. We analysed these simulation data to examine whether the characteristics of a crisis situation were present. Figure 4 shows the evolution of the story in both simulations. Each begins with a winter storm warning, and later the winter storm begins. The situation worsens with cascading effects, including power grid disruption due to ice and/or snow, which induces blackouts in several areas. Therefore, the managers in the simulation must not only handle a bad weather situation but also more serious issues related to transportation and blackouts; thus, the nature of the problem evolves.

The events generate important consequences since many roads were blocked, including cross-border roads; this shut down urban public transport and caused traffic jams and traffic accidents with fatalities. Simultaneously, many trains were blocked, including national and international high-speed trains. Due to the weight of the snow, the roof of a supermarket collapsed. Blackouts occurred here and there throughout the area.

This contextual situation engages the participants mentally and encourages them to imagine many potential consequences. Side events were inserted to surprise the participants. For example, a truck carrying hazardous materials was involved in an accident, and there was an intrusion into a nuclear power plant. The participants were mentally prepared to cope with a winter storm and were therefore surprised when an unrelated event occurred unexpectedly.

The combination of events associated with the storm and unrelated side events helped to create a chaotic situation. When the participants were asked to answer yes or no to whether they experienced a chaotic situation, 59\% of the students and 57\% of professionals replied YES.

Many stakeholders were involved in the crisis situation simulation. In addition to the roles responsible for crisis management in France, the nature of the events and their consequences led to the creation of $37 \%$ (36\% for professionals and 38\% for students) of additional roles such as a weather forecast expert; a regional roads manager; an elementary school director or; a supermarket manager for examples. 


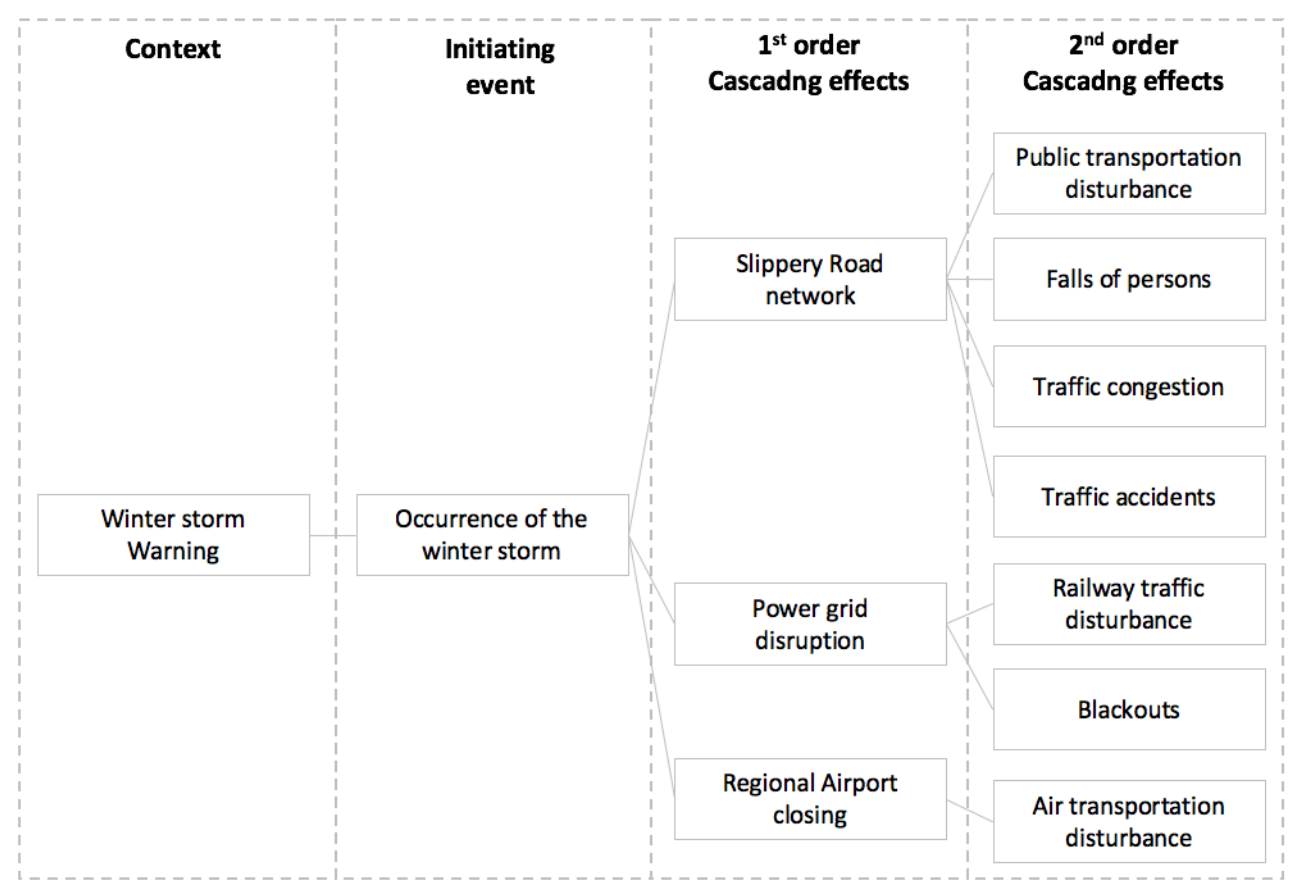

Figure 4. Main issues associated with the scenario experienced by participants during the simulation

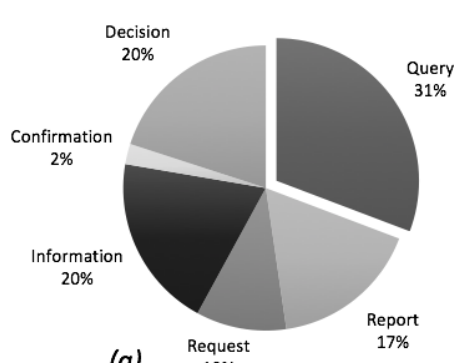

(a)

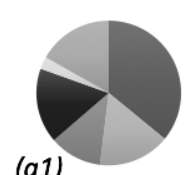

(a1)

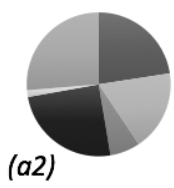

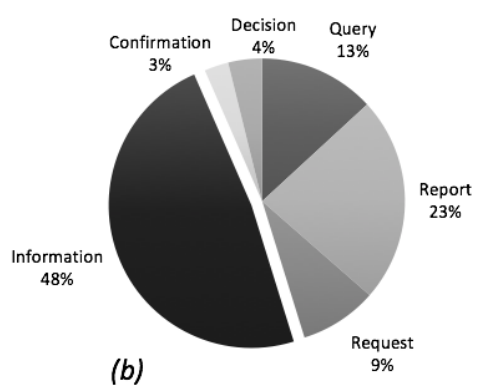

Figure 5. Type of messages sent by the participants (a) and the animation team (b). (a1) Type of messages sent by students; (a2) Type of messages sent by professionals; (b1) Type of messages sent by the animation team to the students; (b2)

Type of messages sent by the animation team to the professionals

Identifying the type of sent messages ("query": ask a question; "report": make a report regarding a known situation; "information": give a new fact; "request": call for something; and "confirmation": make certain what has been announced) shows that the most frequent message type sent by the participants (31\%) was queries (Figure 5). Queries are questions asked by 
participants which aim to get information. This information is indispensable for the crisis teams to help them clarify the situation and create a representation of what is happening. This mechanism contributes to lower the level of uncertainty. To provide the crisis units with information, the animation fulfilled this role by sending $48 \%$ of this message type. We also made a distinction between the simulations with students and professionals (Figure $5 \mathrm{a}$ and $\mathrm{b}$ ). Regarding messages sent by the animation team towards both types of participants (Figure 5 a1 and a2), we note that the animation team received a few more queries from the students regarding the professionals. This emphasizes that each simulation was different in terms of situation management and level of information. It seems normal that the professionals who better know the geography of their municipality and their procedures did not need to make as many queries.
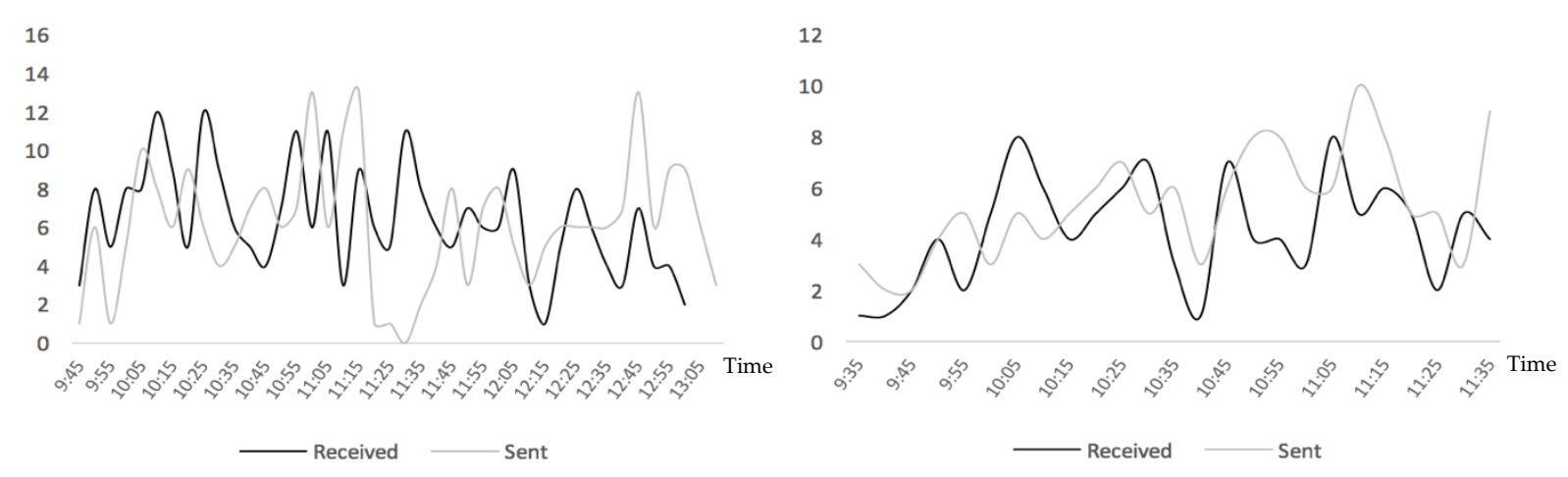

Figure 6. Pace of messages sent or received by participants in the simulation with students (left) and professionals (right)

The irregular rhythm of events during the simulation is shown in Figure 6. It is clear that the pace of information sent and received was irregular in both simulations. The pace oscillates from short periods of inactivity with 0 sent or received messages in 10 minutes to a more rapid rate of 13 sent or received messages in 10 minutes.

Information management is difficult inside a crisis unit room. The capacity of participants to remain concentrated is threatened by the level of noise and management of the high flow of sometimes unclear information. So as not to interfere with verbal communications and complex tasks, a room should have a maximum noise level between 49 and $58 \mathrm{~dB}$ (Hemp et al. 1995). Typical open-office noise conditions, including conversation, typing sounds, ringing phones, and drawers being opened and closed involves an average level of $55 \mathrm{~dB}$ with peaks up to 65 dB (Evans and Johnson 2000; Loewen and Suedfeld 1992). In the crisis units, microphones placed in the middle of the crisis unit table provide an average noise level which is comprised between $60 \mathrm{~dB}$ and $70 \mathrm{~dB}$ with peaks up to almost $100 \mathrm{~dB}$. Under these noise conditions, we assume that the capacity of crisis managers to remain focused is altered. Beyound the environmental conditions influencing the cognitive capabilities of crisis managers, the flow of information that members of crisis units must manage can reveal difficulties. During iCrisis simulations, participants managed an average of 2 (professionals) to 2.5 (students) messages sent and received per minute. Evidence suggests that human cognitive systems have a limited 
working memory capable of holding no more than 5 to 9 pieces of information in a few seconds (Miller 1956). Without repetition, information will be lost after 20 seconds (Bhandary et al. 2016). The quantity of information is not the only issue to be managed; relevant information is also crucial. Relevant information is information that is understood and certified. For example, $21.4 \%$ ( $25 \%$ for the students and $18 \%$ for the professionals) of the messages included abbreviations that could be unfamiliar to certain stakeholders and thus misunderstood. Therefore, although relevant information might have been present in those messages, there were many messages and thus the relevant portions might have been difficult to identify. During crisis situations, the need to be quick influence the quality of the messages that are rarely completely precise. While participants waited for more information, they could not avoid attempting to interpret the first message and forming expectations. For example, a message about a problem at a nuclear plant was interpreted as a radiation issue although it was an intrusion.

As free agents, the journalists took advantage of their mobility to gather information during the simulations. Their objective was to gather information and understand what was occurring to relay the information through social media and other information channels (newspapers, TV, radio). To complete this task, crisis units were visited several times and they received a regular flow of questions during the simulation which contributed to make experience media involvement. For example, one of the crisis units in the simulation carried out with students was visited 7 times. Up to $25 \%$ of the students and $31 \%$ of the professionals found that the journalists were intrusive; additionally, up to $34 \%$ of the students and $86 \%$ of the professionals thought that the media informed the members of the crisis units by transferring information collected from the field (characters played by the animation team). From the field, they received information with a high level of details that is different from the scale at which a strategic crisis unit works contributing to astonish the members of the crisis unit and to give the impression that the media know more about the situation.

\section{Perception of participants' reaction to the simulated crisis situation}

To analyse the reaction of the participants, they were asked to respond to questions using a Likert scale from 1-7 (ranging from "never" to "all the time"). The questions were as follows: "During the simulation, did the course of events arouse astonishment?" (q1); and "During the simulation I noticed changes in relationship between participants" (q2).

Table 3 shows the mean and standard deviation of the answers given by the participants. Mean scores suggest that participants felt each of both characteristics to some extent.

We suggest the following interpretation of the data: responses at level 1 indicate an absence of noticing feelings of surprise due to astonishment and changes in relationship. Responses at levels 2-7 indicate that these states were felt or seen at least once during the simulation (Table 4). The results show that during the simulation, the sequence of events triggered astonishment or surprise (chi-squared $=82.286, \mathrm{p}<.001$ ) and changes in relationships (chi-squared $=30.036$, $\mathrm{p}<.001)$. 
Table 3. Mean and standard deviation of the participants' answers to whether the felt astonishment and changes in relationship

\begin{tabular}{rcc}
\hline Characteristics & Mean (standard deviation) & $N$ \\
\hline Astonishment & $3.92(1.58)$ & 112 \\
Students & $4.15(1.15)$ & 68 \\
Professionals & $3.57(1.61)$ & 44 \\
Changes in relationship & $2.99(1.69)$ & 112 \\
Students & $3.15(1.71)$ & 68 \\
Professionals & $2.75(1.64)$ & 44 \\
\hline
\end{tabular}

The STAI-Y1 test assesses the level of anxiety felt by the participants during the simulation. A total of $31 \%$ of the participants exceeded a threshold of $39-40$ (39.2\% of students and $16 \%$ of professionals). This result is very interesting since it reveals that a significant part of the participants felt state anxiety. In addition to this assessment, observations of the crisis units showed behaviours that could be related to a state of anxiety among the participants. For example, in one crisis unit during the simulation carried out with students, an observer noted 30 instances of behaviours, such as voice intensity, aggressive facial expressions, and nervousness. Even if the STAI-Y1 indicator does not reflect the stress levels observed in the simulations very well, it can help to compare the subjects. Additionally, at the level of the group, even though not every participants can be considered as feeling anxiety in regard to the STAI-Y1 test, it is clear however that anxiety was raised anyhow in the crisis units since $31 \%$ of the participants scored a high rate of anxiety. Eventually, the STAI-Y1 scores are interesting because they are significantly correlated with the results for astonishment (p-value <.01) and changes in relationship ( $\mathrm{p}$-value <.05) despite low association forces (respectively equal to 0.253 and 0.205$)$.

There is no threshold established for the NASA-TLX test to assess the significance of the time pressure experienced by the participants. Using a significance level of $50 \%$ to evaluate time pressure, a test of the median (using the sign method with 63 values $>0.5$ and 53 values $\leq 0.5$ ) results in rejection of the null hypothesis that the median is $\leq 0.5$ with a $p$-value $=0.01$. Therefore, at the 0.05 significance level, we conclude that the perceived temporal pressure was significant.

To the yes or no question ("Do you characterise the experienced situation as a crisis situation?"), 58\% of the participants said "Yes" (64\% of professionals and 54\% of students). This result emphasises that most of the participants felt that they actually experienced a crisis situation. The fact that all participants did not give the same answer even though they experienced the same situation illustrates the relative nature of the simulation, which is characteristic of crisis situations. 
Table 4. Distribution of answers to $\mathrm{q} 1$ and $\mathrm{q} 2$ after transformation of the ordinal variables into nominal variables

\begin{tabular}{cccc}
\hline Characteristics & No & Yes & N \\
\hline Astonishment & 8 & 104 & 112 \\
Students & 2 & 66 & 68 \\
Professionals & 6 & 38 & 44 \\
$\begin{array}{c}\text { Changes in } \\
\text { relationship }\end{array}$ & 27 & 85 & 112 \\
Students & 15 & 53 & 68 \\
Professionals & 12 & 32 & 44 \\
\hline
\end{tabular}

These results show that the characteristics of the crisis can be observed at the scale of the group of participants during an iCrisis simulation. While going into details we observed that different groups, or even different individuals from the same group do not react in the same way (Judek et al. 2018). This is explained by the fact that, each individual is different (experience, environment, state of mind, etc.) and each situation is different generating different reactions and perceptions.

\section{CONCLUSIONS}

Because crisis situations are unpredictable and unique, it is impossible to be prepared for any specific situation. However, decision makers can be prepared to cope with the characteristics and consequences of a crisis situation; specifically, they can be prepared to perceive their own crisis reaction. We have seen that crisis simulation approaches such as iCrisis aims to accomplish this.

The iCrisis simulation approach relies on the assumption that participants can benefit from experiencing the characteristics of a crisis. However, it must be clear at the outset that the participants will experience a crisis situation, as defined earlier, because these are often confused with emergency situations. One can recall that an emergency situation can be simulated through an exercise aiming to assess the implementation of a procedure whereas a crisis simulation rather aims to sensitize participants to crisis characteristics. This is explained with the definition of crisis which brings concepts such as unique, unpredictable, relative to anyone. For this reason, in contrast to an emergency situation, we have seen that a crisis situation cannot be really managed because as soon as the situation is starting to be controlled, it is not a crisis anymore. Thus, we use terminology such as "crisis steering" rather than "crisis management." 
Validation of crisis simulations remains complex. In this study, a clear definition of a crisis was important to set. Although there are many different definitions of crises in the literature, they share common elements that can be used to identify a crisis based on its characteristics. Given these commonalities and the fact that a crisis situation involves both the situation itself and the reaction it induces among the managers, we proposed that crises include these two categories of characteristics. We noted that some characteristics could fall into both categories (e.g., surprise and time pressure), although we made a justified decision to place them in just one based on our interpretation. Most of these characteristics rely on the feelings of the participants which can be surveyed even if they are subjective. This subjectivity means that some of the results are questionable because while comparing subjects or groups of subjects, results can be different. This relies on the fact that each situation is different, because of elements of the scenario as well as each individual, because of their experience and their reaction. However, they enable useful comparisons and analyses and thus constitute a relevant avenue of research.

We showed that the characteristics of the reaction to a crisis could be observed among the participants in iCrisis simulations. Assuming that verifying the reaction of participants being congruent with the stated characteristics allow to think that the situation was simulated well, we conclude that iCrisis simulation approaches enables to reproduce the aforementioned characteristics of a crisis.

Due to the fact that there is very little research conducted on the topic of crisis simulation validation, we assume that this study was exploratory. However, the questions explored here are important because crisis simulations are widely used for training and research due to the crucial issues encountered by organizations during a crisis. Therefore, although crisis situations have subjective characteristics, our results emphasize that it is possible to observe whether a simulation reproduces the characteristics of a crisis situation.

Our study has several limitations, such as the difficulty in defining a crisis and the arbitrary, but justified, nature of categorizing crisis characteristics. The wide range of existing simulation approaches makes it difficult to propose a standard methodology. Moreover the use of indicators, such as STAI-Y1, may not always be helpful because of the difficulty in setting appropriate thresholds. Then for each parameter, a study to identify the most appropriate method observation/assessment must be carry out in order to optimize the general methodology.

Even though it was not an objective of this study, the presentation of both results from professionals and students showed that there were major differences between these two types of participants certainly because of environmental factors, different levels of experience and individual capabilities. This is an interesting outcome that should be further studied because here the process of simulating a crisis situation seemed to put at the same level both groups.

We assume that simulations are a useful way to gain experience and that the use of such tools and/or approaches is beneficial for managers. Validation can help increase the credibility of simulations and managers' willingness to use them. Our results emphasize that although crisis situations have subjective characteristics, it is anyhow possible to design a protocol to evaluate them. This study can be considered as innovative due to the will to make a complete evaluation of the simulator's approach capability to create crisis conditions. The limits that 
carries this study must be an opportunity for future research to improve this protocol of evaluation since it appears as an interesting starting point.

\section{ACKNOWLEDGEMENTS}

We thank the Seventh Framework Programme EU Project CascEff-Modelling of dependencies and cascading effects for emergency management in crisis situations (Grant Agreement No: 607665) for financial support and for reviewing this paper. We also thank Dr. Jan-Cédric Hansen and Joan Belo for their involvement and their help in carrying out the iCrisis simulations.

\section{REFERENCES}

Addolorato, G., Ancona, C., Capristo, E., et al (1999) State and trait anxiety in women affected by allergic and vasomotor rhinitis. J Psychosom Res, 46: 283-289

Amabile, T. M., Schatzel, E. A., Moneta, G. B., Kramer, S. J. (2004) Leader behaviors and the work environment for creativity: Perceived leader support. Leadersh Q, 15: 5-32. doi: 10.1016/j.leaqua.2003.12.003

Anand, V., Manz, C. C., Glick, W. H. (1998) An organizational memory approach to information management. Acad Manage Rev, 23: 796-809. doi:

10.5465/AMR.1998.1255639

Bhandary, S. P., Lipps, J., Winfield, S. R., et al (2016) NASA Task Load Index Scale to Evaluate the Cognitive Workload during Cardiac Anesthesia Based Simulation Scenarios. Int J Anesth Res, 4: 300-304.

Billings, R. S., Milburn, T. W., Schaalman, M.L. (1980) A model of crisis perception: A theoretical and empirical analysis. Adm Sci Q, 300-316. doi:

$10.1177 / 009539978301500202$

Boin, A. (2004) Lessons from Crisis Research. Int Stud Rev, 6: 165-194. doi: 10.1111/j.15219488.2004.393_2.x

Boin, A., Kuipers, S., Overdijk, W. (2013) Leadership in times of crisis: a framework for assessment. Int Rev Public Adm, 18: 79-91

Borodzicz, E., Van Haperen, K. (2002) Individual and Group Learning in Crisis Simulations. J Contingencies Crisis Manag, 10: 139-147. doi: 10.1111/1468-5973.00190

Borodzicz, E. P. (2004) The Missing Ingredient is the Value of Flexibility. Simul Gaming 35: 414-426. doi: 10.1177/1046878104266221

Bruchon-Schweitzer, M., Paulhan, I. (1993) Manuel de l'inventaire d'anxiété état-trait forme Y (STAI-Y). Adapté Par Bruchon-Schweitzer Paulhan Paris 
Bundy, J., Pfarrer, M. D. (2015) A Burden of Responsibility: The Role of Social Approval at the Onset of a Crisis. Acad Manage Rev, 40: 345-369. doi: 10.5465/amr.2013.0027

Carmeli, A., Schaubroeck, J. (2008) Organisational Crisis-Preparedness: The Importance of Learning from Failures. Long Range Plann, 41: 177-196. doi: 10.1016/j.lrp.2008.01.001

Cesta, A., Cortellessa, G., De Benedictis, R. (2014) Training for crisis decision making - An approach based on plan adaptation. Knowl-Based Syst, 58: 98-112. doi: 10.1016/j.knosys.2013.11.011

Dautun, C., Tixier, J., Chapelain, J., et al (2007) Crisis management : improvement of knowledge and development of a decision aid process. In: 12. International Symposium on Loss Prevention and Safety Promotion in the Process Industry. IChemE, Edimbourg, United Kingdom, p 6

Davis, G.B., Davis, G.B. (1999) The Blackwell Encyclopedia of Management and Encyclopedic Dictionaries, The Blackwell Encyclopedic Dictionary of Management Information Systems. John Wiley \& Sons

Evans, G.W., Johnson, D. (2000) Stress and open-office noise. J Appl Psychol, 85: 779-783. doi: 10.1037/0021-9010.85.5.779

Farazmand, A. (2001) Handbook of crisis and emergency management. CRC Press

Feinstein, A.H., Cannon, H.M. (2002) Constructs of Simulation Evaluation. Simul Gaming, 33: 425-440. doi: 10.1177/1046878102238606

Fink, S. (1986) Crisis Management: Planning for the Inevitable. American Management Association

Fink, S., Beak, J., Taddeo, K. (1971) Organizational crisis and change. J Appl Behav Sci, 7: 15-37. doi: 10.1177/002188637100700103

Flin, R. H. (1996) Sitting in the hot seat: Leaders and teams for critical incident management. Wiley

Gredler, M. (1992) Designing and evaluating games and simulations: A process approach. Kogan Page London

Hadley, C. N., Pittinsky, T. L., Sommer, S. A., Zhu, W. (2011) Measuring the efficacy of leaders to assess information and make decisions in a crisis: The C-LEAD scale. Leadersh, $Q$ 22: 633-648. doi: 10.1016/j.leaqua.2011.05.005

Hart, S. G., Staveland, L. E. (1988) Development of NASA-TLX (Task Load Index): Results of empirical and theoretical research. Adv Psychol, 52: 139-183

Hartley, D. S. (1997) Verification \& validation in military simulations. In: Proceedings of the 29th conference on Winter simulation - WSC '97. ACM Press, Atlanta, Georgia, United States, pp 925-932 
Hemp, W., Glowatz, M., Lichtenwalner, C. (1995) Curing the Noisy Office. Occup Hazard, 57: 36

Hermann, C. F. (1963) Some consequences of crisis which limit the viability of organizations. Adm Sci Q, 61-82

Hermann, C. F. (1969) Crises in Foreign Policy. Simul Anal Indianap,

Hermann, C. F. (1972) International crises; insights from behavioral research. Free Press

Judek, C., Verhaegen, F., Belo, J., Verdel, T. (2018) Crisis Managers' Workload Assessment During a Simulated Crisis Situation. In: Malizia A., D'Arienzo M. (eds) Enhancing CBRNE Safety \& Security: Proceedings of the SICC 2017 Conference. Springer, Cham, doi: 10.1007/978-3-319-91791-7_37

Kim, H., Lee, J. (2011) A Critical Review of Current Crisis Simulation Methodology. Int J Contents 7: 58-64. doi: 10.5392/IJoC.2011.7.1.058

Knight, R. G., Waal-Manning, H. J., Spears, G. F. (1983) Some norms and reliability data for the State-Trait Anxiety Inventory and the Zung Self-Rating Depression scale. Br J Clin Psychol, 22: 245-249

Kovoor-Misra, S. (1995) A multidimensional approach to crisis preparation for technical organizations: Some critical factors. Technol Forecast Soc Change 48: 143-160. doi: 10.1016/0040-1625(94)00041-T

Kovoor-Misra, S., Clair, J. A., Bettenhausen, K. L. (2001) Clarifying the Attributes of Organizational Crises. Technol Forecast Soc Change 67: 77-91. doi: 10.1016/S00401625(99)00081-5

Lagadec, P. (1993) Preventing chaos in a crisis. McGraw-Hill

Lagadec, P. (1991) La gestion des crises : Outils de réflexion à l'usage des décideurs. Ediscience Int Paris 300

Lalonde, C., Roux-Dufort, C. (2013) Challenges in Teaching Crisis Management Connecting Theories, Skills, and Reflexivity. J Manag Educ, 37: 21-50. doi: $10.1177 / 1052562912456144$

Lazarus, R. S., Folkman, S. (1984) Stress, appraisal, and coping. Springer publishing company

Loewen, L. J., Suedfeld, P. (1992) Cognitive and arousal effects of masking office noise. Environ Behav, 24: 381-395

Milburn, T. W. (1972) The management of crisis. Int Crises Insights Behav Res, NY USA 262

Milburn, T. W., Schuler, R. S., Watman, K. H. (1983) Organizational crisis. Part I: Definition 
and conceptualization. Hum Relat, 36: 1141-1160

Miller, G. A. (1956) The magical number seven plus or minus two: some limits on our capacity for processing information. Psychol Rev, 63: 81-97

Miller, K., Iscoe, I. (1963) The Concept of Crisis: Current Status and Mental Health Implications. Hum Organ, 22: 195-201. doi: 10.17730/humo.22.3.672776528107trh7

Nystrom, P. C., Starbuck, W. H. (1984) To avoid organizational crises, unlearn. Organ Dyn, 12: 53-65. doi: 10.1016/0090-2616(84)90011-1

Pauchant TC, Douville R (1993) Recent research in crisis management: a study of 24 authors' publications from 1986 to 1991. Organ Environ, 7: 43-66. doi: $10.1177 / 108602669300700104$

Pauchant, T. C., Mitroff, I.I. (1992) Transforming the crisis-prone organization: Preventing individual, organizational, and environmental tragedies. Jossey-Bass

Pearson, C. M., Clair, J. A. (1998) Reframing Crisis Management. Acad Manage Rev, 23: 59-76. doi: 10.5465/AMR.1998.192960

Pearson, C. M., Mitroff, I. I. (1993) From crisis prone to crisis prepared: A framework for crisis management. Acad Manag Exec, 7: 48-59. doi: 10.5465/AME.1993.9409142058

Perghel, R., Psychogios, A. G. (2013) Making Sense of Crisis: Cognitive Barriers of Learning in Critical Situations. Manag Dyn Knowl Econ, 1

Quarantelli, E. L. (1988) Disaster Crisis Management: A Summary of Research Findings. J Manag Stud, 25: 373-385. doi: 10.1111/j.1467-6486.1988.tb00043.x

Ramboatiana, S., Roux-Dufort, C. (2006) Les crises organisationnelles, fievre ou cholera? Prev Secur, 21-25

Reid, J. L. (2000) Crisis Management: Planning and Media Relations for the Design and Construction Industry. John Wiley \& Sons

Rosenthal, U., Boin, R. A., Comfort, L. K. (2001) The changing world of crises and crisis management. Manag Crises Threats Dilemmas Oppor, 5-27

Rosenthal, U., Charles, M. T., Hart, P. (1989) Coping with crises: The management of disasters, riots, and terrorism. Charles C Thomas Pub Ltd

Selye, H. (1956) The stress of life. McGraw-Hill, New York, NY, US

Shrivastava, P., Mitroff, I. I., Miller, D., Miclani, A. (1988) Understanding Industrial Crises. J Manag Stud, 25: 285-303. doi: 10.1111/j.1467-6486.1988.tb00038.x

Smart, C., Vertinsky, I. (1984) Strategy and the environment: A study of corporate responses to crises. Strateg Manag J, 5: 199-213 
Sniezek, J. A., Wilkins, D. C., Wadlington PL (2001) Advanced training for crisis decision making: simulation, critiquing, and immersive interfaces. In: System Sciences, 2001. Proceedings of the 34th Annual Hawaii International Conference on. IEEE

Sniezek, J. A., Wilkins, D. C., Wadlington, P. L., Baumann, M. R. (2002) Training for crisis decision-making: Psychological issues and computer-based solutions. J Manag Inf Syst, 18: $147-168$

Sommer, A., Pearson, C. M. (2007) Antecedents of creative decision making in organizational crisis: A team-based simulation. Technol Forecast Soc Change 74: 12341251. doi: 10.1016/j.techfore.2006.10.006

Spielberger, C. D. (1983) Manual for the State-Trait Anxiety Inventory STAI (form Y)(“ selfevaluation questionnaire")

Starbuck, W. H., Greve, A., Hedberg, B. (1978) Responding to crises. J Bus Adm, 9: 111-137

Tena-Chollet, F. (2012) Elaboration d'un environnement semi-virtuel de formation à la gestion stratégique de crise, basé sur la simulation multi-agents. Ecole des Mines de SaintEtienne

Tena-Chollet, F., Tixier, J., Dandrieux, A., Slangen, P. (2016) Training decision-makers: Existing strategies for natural and technological crisis management and specifications of an improved simulation-based tool. Saf Sci, doi: 10.1016/j.ssci.2016.03.025

Ulmer, R. R., Sellnow, T. L., Seeger, M. W. (2013) Effective Crisis Communication: Moving From Crisis to Opportunity. SAGE Publications

Verdel, T., Tardy, A., Lopez, P., et al (2010) Crisis $^{\mathrm{TM}}$ : un dispositif original de simulation de gestion de crise. Congrès Lambda Mu 17, La Rochelle. IMdR

Wiener, A. J., Kahn, H. (1962) Crisis and arms control. Hudson Institute

Yusko, K. P., Goldstein, H. W. (1997) Selecting and Developing Crisis Leaders Using Competency-Based Simulations. J Contingencies Crisis Manag, 5: 216-223

Zhang, Z., Jia, M., Gu, L. (2012) Transformational leadership in crisis situations: evidence from the People's Republic of China. Int J Hum Resour Manag, 23: 4085-4109. doi: 10.1080/09585192.2011.639027 